\title{
Synthesis and Characterization of Molybdenum Phthalocyanine as Target Material for High Specific Activity Molybdenum-99 Production
}

\author{
Muhamad Basit Febriann ${ }^{1, *}$, Duyeh Setiawan ${ }^{1}$, and Hilda Hidayati ${ }^{2}$ \\ ${ }^{1}$ Center for Applied Science and Nuclear Technology, National Nuclear Energy Agency, \\ Jl. Tamansari No. 71, Bandung 40132, West Java, Indonesia \\ ${ }^{2}$ Department of Chemical Engineering, Bandung State Polytechnic, \\ Jl. Gegerkalong Hilir, Ds. Ciwaruga, Bandung 40559, West Java, Indonesia
}

*Corresponding author:

email:mbasitf@batan.go.id

Received: February 13, 2018

Accepted: January 1, 2019

DOI: $10.22146 /$ ijc.33218

\begin{abstract}
High specific activity is a necessity in the fabrication of ${ }^{99} \mathrm{Mo} /{ }^{99 m} \mathrm{Tc}$ radioisotope generators. Recoil reaction with molybdenum phthalocyanine (Mo-Pc) target material is a method that could be used as an alternative method for increasing specific activity in ${ }^{99}$ Mo production in light of tightening regulation of highly enriched uranium irradiation. Mo-Pc was synthesized via solid-state reaction between ammonium heptamolybdate and phthalonitrile in a reflux system at $300{ }^{\circ} \mathrm{C}$ for $3 \mathrm{~h}$. This optimum condition was identified after performing several variations of temperature and time of reaction, considering FTIR spectra, the yield of product and melting point of the product. XRD measurement showed that Mo-Pc synthesized at optimum condition was free from $\mathrm{MoO}_{2}$, phthalimide and unreacted molybdenum. Mo-Pc has UV-vis properties of Q-band absorption between 600 and $750 \mathrm{~nm}$ when dissolved in tetrahydrofuran, dimethylformamide and trifluoroacetic acid. In the preliminary study of irradiation of $1 \mathrm{~g}$ Mo-Pc at $3.5 \times 10^{12} \mathrm{ncm}^{-2} \mathrm{~s}^{-1}$ neutron flux, followed by dissolution in tetrahydrofuran and extraction of ${ }^{99} \mathrm{Mo}$ into $\mathrm{NaOH}$, we obtained ${ }^{99} \mathrm{Mo}$ solution with a specific activity of 682.35 $m \mathrm{Ci} / \mathrm{g} \mathrm{Mo}$, this being 254.61 times higher than in the regular $\mathrm{MoO}_{3}$ target.
\end{abstract}

Keywords: recoil; high specific activity; phthalocyanine; characterization

\section{- INTRODUCTION}

Successful application of technetium-99m $\left({ }^{99 \mathrm{~m}} \mathrm{Tc}\right)$ as the most commonly used medical radioisotope reflects the successful development of radioisotope generators using the fission products of highly enriched uranium (HEU) [1-3]. Users of ${ }^{99 \mathrm{~m}} \mathrm{Tc}$ are highly dependent on ${ }^{99} \mathrm{Mo}$ supply from five main research reactors, and aging and maintenance schedules for these reactors has led some researchers to seek alternative supply routes to secure ${ }^{99 m}$ Tc supply [3-4]. As well as optimizing low-enriched uranium (LEU) as a substitute for HEU, some researchers have revisited the reactor activation route for ${ }^{98} \mathrm{Mo}$ to provide ${ }^{99}$ Mo.

The main obstacle of this activation route for ${ }^{99} \mathrm{Mo}$ is the low specific activity of ${ }^{99} \mathrm{Mo}$ targets (300$1000 \mathrm{mCi} / \mathrm{g})$ compared to $\mathrm{HEU}$ targets $\left(10^{4} \mathrm{Ci} / \mathrm{g}\right)$. In order to achieve adequate activation of ${ }^{99} \mathrm{Mo}$, the amount of molybdenum target must be increased. In contrast, the bound capacity of the most commonly used alumina columns is limited, at only $20 \mathrm{mg} \mathrm{Mo} / \mathrm{g}$ of alumina, meaning that more alumina and more eluent are needed to separate and elute ${ }^{99 \mathrm{~m}} \mathrm{Tc}$ from ${ }^{99} \mathrm{Mo}$. Several studies of sorbent materials with higher molybdenum-binding capacity and of other methods of radioisotope generation have been conducted [2,5], but these have yet to be widely used. Other studies have sought to use the ability of recoil reactions to increase the specific activity of neutron-activated ${ }^{99} \mathrm{Mo}$ [6-7].

When a thermal neutron is captured in a target nucleus only thermal energies are involved and these are far from sufficient to cause chemical changes; however, when a gamma ray is emitted from a slow-moving compound nucleus, chemical changes may occur. This 
effect (the Szilard-Chalmers effect) can cause persistent chemical changes [8].

When irradiated, Mo atoms undergo transmutation from stable ${ }^{98} \mathrm{Mo}$ isotopes to radioactive ${ }^{99} \mathrm{Mo}$ isotopes. When ${ }^{99} \mathrm{Mo}$ is formed, the Szilard-Chalmers effect occurs as the nuclei achieve an excited state following neutron capture and during radiation of $\gamma$-quants, radiating recoil energy of E0 30-100 eV [8]. Recoil energy is much greater than the energy of the chemical bond of the atom in the crystal structure, so the radioactive ${ }^{99} \mathrm{Mo}$ atoms will be freed from the initial molybdenum compound structure, but stable ${ }^{98} \mathrm{Mo}$ will remain as the initial compound. One of the likely compounds in which recoil reactions could take place is phthalocyanine.

Fig. 1 shows the Mo-Pc structure in which phthalocyanine is a ring structure built of four isoindole units. Each isoindole is connected to each other by an $\mathrm{N}$ aza atom. A metal atom, in this case, molybdenum, usually exists in the center of phthalocyanine and is connected to the ring via four Mo-N bonds. The Mo-N bond could be broken by recoil energy in the SzilardChalmers reaction and Mo-Pc could be synthesized in a number of ways, either with or without solvent. Precursor o-cyanobenzamide, diamino phthalimide or phthalic acid could be used for phthalocyanine synthesis but this process would require the presence of a solvent. In contrast, phthalocyanine could be synthesized without solvent in ring formation by heating phthalonitrile and ammonium heptamolybdate.

Some studies of phthalocyanine compounds and their characteristics have been carried out, but none of them (a)

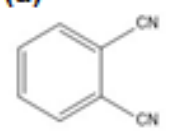

(b)

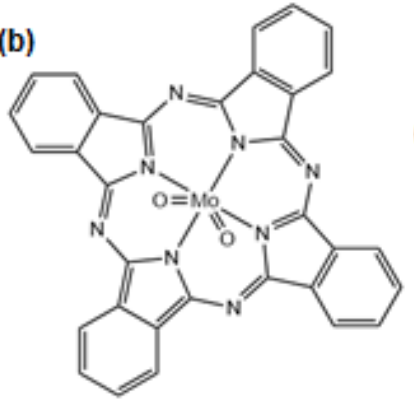

(c)

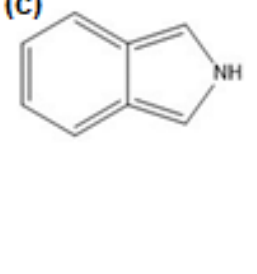

Fig 1. Compound structures: (a) phthalonitrile; (b) molybdenum phthalocyanine; (c) isoindole have explained Mo-Pc characteristics, thus in this study synthesis of Mo-Pc and its characterization has been carried out. The purpose is to identify the optimum condition for Mo-Pc synthesis and to identify important characteristics of Mo-Pc, such as FTIR spectra, crystallography by XRD, solubility in various solvents and UV-vis absorbance in those solvents. These Mo-Pc characteristics would be basic information for use in future studies of irradiation of Mo-Pc and separation of ${ }^{99}$ Mo from irradiated Mo-Pc.

\section{- EXPERIMENTAL SECTION}

\section{Materials}

Ammonium heptamolybdate p.a. $\left(\left(\mathrm{NH}_{4}\right)_{6} \mathrm{Mo}_{7} \mathrm{O}_{24} \cdot 4 \mathrm{H}_{2} \mathrm{O}\right)$, phthalonitrile p.a. $\left(\mathrm{C}_{6} \mathrm{H}_{4} \mathrm{~N}_{2}\right)$, sulphuric acid 98\%, dimethylformamide p.a. (DMF), tetrahydrofuran p.a. (THF), trifluoroacetic acid p.a. (TFA), and absolute ethanol were purchased from Merck Millipore. NaOH 0.5 M, TGA solution 10\% and potassium thiocyanate (KSCN) solution $10 \%$ were prepared by dissolution in distilled water. Whatman filter paper no.1 was used in the filtration process.

\section{Instrumentation}

The following equipment was used in this research: reflux system, heating mantle, magnetic stirrer, fume hood, balance (Mettler Toledo, five digits) UV-vis spectrophotometer (Hitachi), quartz cuvette (Q Analytics), XRD (PANalytical X'Pert 3), FTIR spectrometer (Shimadzu) and melting point apparatus (Fischer Scientific).

\section{Procedure}

Mo-Pc was prepared by solid-state reaction between ammonium heptamolybdate $\left(\left(\mathrm{NH}_{4}\right)_{6} \mathrm{Mo}_{7} \mathrm{O}_{24} \cdot 4 \mathrm{H}_{2} \mathrm{O}\right)$ and phthalonitrile $\left(\mathrm{C}_{6} \mathrm{H}_{4}(\mathrm{CN})_{2}\right.$, Merck). The molar composition ratio between molybdenum and phthalonitrile was 1:4, at $1.765 \mathrm{~g}$ and $5.125 \mathrm{~g}$ respectively. The reaction was carried out in a ventilated reflux system in a round flask equipped with a quicksilver thermometer and condenser and heated using a heating mantle. 


\section{Optimization of temperature and time of reaction}

Optimization of the reaction was carried out by varying temperature and time of reaction. Based on Wolfram's phthalocyanine synthesis condition [9] $\left(300^{\circ} \mathrm{C}\right.$, $3 \mathrm{~h}$ ), reaction temperatures were varied at 275,300 , and $325^{\circ} \mathrm{C}$ for $3 \mathrm{~h}$, and time of reaction was varied at 60,120 , 180 , and $240 \mathrm{~min}$ after the optimum temperature was obtained.

\section{Purification of Mo-PC}

Purification was carried out by washing the solid formed with hot water containing $1 \mathrm{M}$ potassium hydroxide, to remove any unreacted molybdenum. Then ethanol and acetone were used to remove unreacted phthalonitrile and phthalimide until the washings were colorless [9-10]. Using a few drops of filtrate as the sample, several spot tests for molybdenum were conducted with TGA $10 \%$, concentrated $\mathrm{HCl}$ and $\mathrm{KSCN}$ $10 \%$. Orange color in the spot test indicated a positive result for molybdenum content. Mo-Pc solid was washed with water until spot-test results were colorless. Mo-Pc solid was dried in an oven at $40{ }^{\circ} \mathrm{C}$ for $4 \mathrm{~h}$ and weighed and re-dried in a desiccator until its weight was constant.

\section{Characterization of synthesis products}

Melting points of the compounds were measured using Fischer Scientific melting point apparatus. FTIR spectra of the compounds were recorded by Shimadzu FTIR using the transmission technique, by creating Mo$\mathrm{Pc}$ in $\mathrm{KBr}$ pellets. XRD patterns of solids were recorded by PANalytical X'Pert Pro XRD. UV-vis spectrophotometric method using a Hitachi spectrophotometer was applied to determine molybdenum content in solution [11]. FTIR and XRD setup parameters are shown in Table 1.

\section{V-vis absorption properties of Mo-PC}

Saturated solutions of Mo-Pc were prepared by dissolving an amount of Mo-Pc in selected solvents until precipitation occurred. Selection of solvent (sulphuric acid $98 \%$, DMF, THF, and TFA) was based on a previous study [12]. Dissolution was carried out by shaking and stirring at room temperature, but with the use of an ice bath for dissolution with sulphuric acid. Supernatant and precipitation of undissolved Mo-Pc were separated by
Table 1. Setup parameters of FTIR and XRD measurement

\begin{tabular}{ll}
\hline FTIR properties (Shimadzu) \\
\hline Scan range $\left(\mathrm{cm}^{-1}\right)$ & $4500-500$ \\
Resolution $\left(\mathrm{cm}^{-1}\right)$ & 4 \\
Number of data points & 8192 \\
Number of scans & 64 \\
\hline XRD properties (X’Pert Pro) \\
\hline$\lambda$ of the X-ray source & $1.540598 \AA(\mathrm{Cu} \mathrm{Ka})$ \\
Scan range $(2 \theta)$ & 5 to $90^{\circ}$ \\
Step angle & $0.01^{\circ}$ \\
Time of step & $1 \mathrm{sec}$ \\
Detector & $\mathrm{PW} 3011$ (sealed proportional gas) \\
\hline
\end{tabular}

centrifugation and the supernatant was measured using a UV-vis spectrophotometer.

\section{A preliminary study of Mo-Pc irradiation}

One gram of synthesized Mo-Pc at optimized condition was weighed and transferred into a quartz ampoule and sealed by glass welding. Ampoules were packed into capped aluminum capsules before being inserted into irradiation position at the TRIGA 2000 research reactor, Bandung. Mo-Pc was irradiated for 72 $\mathrm{h}$ with $3.63 \times 10^{12} \mathrm{n} \mathrm{cm}^{-2} \mathrm{~s}^{-1}$ neutron flux. At the end of irradiation, the target was cooled for $48 \mathrm{~h}$ then transferred into a radioisotope processing box shielded with lead. Irradiated Mo-Pc was dissolved in $50 \mathrm{~mL}$ tetrahydrofuran and stirred at room temperature for $3 \mathrm{~h}$. The Mo-Pc suspension was then filtered through Whatman no. 1 filter paper. Radioactivity of Mo-99 in the filtrate and sediment was measured using a dose calibrator.

Mo-99 in THF medium in the filtrate was extracted into $3 \mathrm{M} \mathrm{NaOH}$ and its radioactivity in the $\mathrm{NaOH}$ medium was measured by dose calibrator. Mo-99 radioisotope solution was then allowed to decay for 1 month prior to molybdenum content determination by the spectrophotometric method.

\section{- RESULTS AND DISCUSSION}

Molybdenum phthalocyanine can be prepared by several reactions, mainly solvent reactions [9-11], solventless reactions or solid-state reactions [9]. By 
using o-phthalonitrile instead of its dinitrile precursor [12], the synthesis pathway could be simplified by using just two reactants.

When two solid reagents were heated, phthalonitrile melted at around $140{ }^{\circ} \mathrm{C}$. At $200{ }^{\circ} \mathrm{C}$, a brown liquid formed and this was followed by vigorous gas evolution at $240{ }^{\circ} \mathrm{C}$, so the reaction must be performed in an open reflux system. This gas evolution may have occurred because the reaction between molybdenum and phthalonitrile had started, giving $\mathrm{NH}_{3}$ gas as a by-product: $\left(\mathrm{NH}_{4}\right)_{6} \mathrm{Mo}_{7} \mathrm{O}_{24} \cdot 4 \mathrm{H}_{2} \mathrm{O}+28 \mathrm{C}_{8} \mathrm{H}_{4} \mathrm{~N}_{2} \rightarrow$ $7 \mathrm{C}_{32} \mathrm{H}_{16} \mathrm{~N}_{8} \mathrm{MoO}_{2}+6 \mathrm{NH}_{3}+7 \mathrm{H}_{2} \mathrm{O}$

The reason for using ammonium heptamolybdate instead of molybdenum trioxide is that molybdenum (VI) could be reduced to $\mathrm{Mo}(\mathrm{V})$ by the formation of ammonia, but there was no synthesis reaction of Mo-Pc when molybdenum trioxide replaced ammonium heptamolybdate. Temperature and time of reaction were varied to find the optimum reaction condition.

\section{Optimization of Temperature and Time of Reaction}

Optimization was investigated at three different temperatures. The results, as presented in Table 2, show that heating at $275^{\circ} \mathrm{C}$ gave a brighter color of synthesis product compared to heating at 300 and $325^{\circ} \mathrm{C}$. Lower reaction temperature resulted in a brighter greyish-blue solid and a lower yield of product compared to higher reaction temperature. Higher temperature gives more kinetic energy, enabling reactants to undergo complete reaction. Melting point test results showed that all products in the temperature variations were different from the initial melting point of the reagent (phthalonitrile and ammonium heptamolybdate). All products sublimated at $380-400{ }^{\circ} \mathrm{C}$ to a bright violet product. The FTIR peak list presented in Table 3 shows that the product at $300{ }^{\circ} \mathrm{C}$ has similar spectral characteristics to zinc phthalocyanine $(\mathrm{Zn}-\mathrm{Pc})$ as a reference spectrum. The peaks at 891 and $968 \mathrm{~cm}^{-1}$ were the signals for Mo- $\mathrm{N}$ and $\mathrm{Mo}=\mathrm{O}$ bonds respectively, whereas the peaks at 950 and $881 \mathrm{~cm}^{-1}$ indicated that $\mathrm{Zn}=\mathrm{O}$ and $\mathrm{Zn}-\mathrm{N}$ bonds in $\mathrm{Zn}-\mathrm{Pc}$ existed. By Hooke's law calculation, we can conclude that vibration frequency $(\mathrm{v})$ of $\mathrm{Zn}=\mathrm{O}$ or $\mathrm{Zn}-\mathrm{N}$ is lower than $\mathrm{Mo}=\mathrm{O}$ and $\mathrm{Mo}-\mathrm{N}$ because $\mathrm{Zn}$ has a lower reduction mass than Mo.

Those peaks do not appear completely in the 275 and $325^{\circ} \mathrm{C}$ products. In the $275^{\circ} \mathrm{C}$ product, the Mo- $\mathrm{N}$ peak appeared but $\mathrm{Mo}=\mathrm{O}$ did not. In contrast to the 275 ${ }^{\circ} \mathrm{C}$ product, $\mathrm{Mo}=\mathrm{O}$ peak appeared at $325^{\circ} \mathrm{C}$ but $\mathrm{Mo}-\mathrm{N}$ did not. According to Achar [13], after being heated from 500 to $1000^{\circ} \mathrm{C}, \mathrm{Cu}-\mathrm{N}$ bonds in $\mathrm{Cu}$-phthalocyanine

Table 2. Reaction temperature optimization in molybdenum phthalocyanine synthesis

\begin{tabular}{lllc}
\hline Reaction temp. $\left({ }^{\circ} \mathrm{C}\right)$ & Synthesis product & Melting point $\left({ }^{\circ} \mathrm{C}\right)$ & Yield $(3$ replicates $)$ \\
\hline 275 & Greyish-blue solid & Sublimated at 380 & $69.08 \pm 6.99 \%$ \\
300 & Bluish-violet solid & Sublimated at 400 & $82.35 \pm 2.25 \%$ \\
325 & Dark bluish-violet solid & Sublimated at 400 & $84.45 \pm 2.52 \%$ \\
\hline
\end{tabular}

Table 3. Peaks in FTIR analysis of synthesis products (temperature variation)

\begin{tabular}{cccc}
\hline Mo-Pc $\left(\mathrm{cm}^{-1}, 275^{\circ} \mathrm{C}\right)$ & Mo-Pc $\left(\mathrm{cm}^{-1}, 300^{\circ} \mathrm{C}\right)$ & $\mathrm{Mo}-\mathrm{Pc}\left(\mathrm{cm}^{-1}, 325^{\circ} \mathrm{C}\right)$ & $\mathrm{Zn}-\mathrm{Pc}\left(\mathrm{cm}^{-1}\right.$, standard $)$ \\
\hline 725 & 725 & 725 & 723 \\
748 & 777 & 779 & 775 \\
N/A & 841 & 839 & N/A \\
889 & 891 & N/A & 881 \\
941 & N/A & N/A & N/A \\
N/A & 968 & 968 & 951 \\
N/A & 1117 & N/A & 1117 \\
1188 & 1159 & 1159 & 1165 \\
1284 & 1286 & 1284 & 1283 \\
1329 & 1329 & 1329 & 1331 \\
\hline
\end{tabular}


polymer are degraded. Thus, Mo-N peak appeared at the lower synthesis temperature and degraded at the higher synthesis temperature. $\mathrm{Mo}=\mathrm{O}$ bond was formed as an oxidation product of Mo. Despite having the highest yield, the $325^{\circ} \mathrm{C}$ product does not have an IR peak from the $\mathrm{Mo}=\mathrm{N}$ bond. Based on the FTIR results presented in Table 3, $300{ }^{\circ} \mathrm{C}$ was considered as the optimum temperature for Mo-Pc synthesis.

Optimization of reaction time was carried out at a reaction temperature of $300{ }^{\circ} \mathrm{C}$ with a time of reaction being measured from the commencement of heating. From the results of reaction-time optimization presented in Table 4, it can be seen that 180 min gave a higher product yield than $240 \mathrm{~min}$ of reaction. It is assumed that some of the product might have sublimated or been destroyed by longer heating time, but this must be proved by supporting references and further analysis. All product did not undergo melting but sublimated at temperatures above $380{ }^{\circ} \mathrm{C}$.
The product at $180 \mathrm{~min}$ has the most complete IR peak. $\mathrm{Mo}=\mathrm{O}$ and $\mathrm{Mo}-\mathrm{N}$ peaks at 970 and $891 \mathrm{~cm}^{-1}$, respectively, did not appear in the 60- and 120-min spectra, possibly because there was not enough time to establish complete $\mathrm{Mo}=\mathrm{O}$ and $\mathrm{Mo}-\mathrm{N}$ bonds in the phthalocyanine core. The 240-min product has the same IR peak pattern as the 180-min product (Fig. 2) but the yield of the 240-min product was slightly lower. In consideration of the shorter time giving equal product properties, $180 \mathrm{~min}$ was selected as the reaction time for the Mo-Pc synthesis procedure.

\section{XRD Characteristics of Mo-Pc}

The XRD pattern of Mo-Pc synthetized in optimum conditions (Fig. 3) showed strong diffraction lines at the following values of $2 \theta: 7.16,9.42,10.82$, $12.28,18.88,23.84,26.38$, and $28.18^{\circ}$, matching with the following diffraction lines from Wolfram's phthalocyanine [8]: $7,9,10.5,12.5,18.9,23.6,26$, and $28^{\circ}$.

Table 4. Reaction-time optimization in molybdenum phthalocyanine synthesis

\begin{tabular}{lllc}
\hline Reaction time (min) & Synthesis product & Melting point $\left({ }^{\circ} \mathrm{C}\right)$ & Yield (3 replicates) \\
\hline 60 & Grey solid & Sublimated at $\sim 380$ & $73.03 \pm 1.43 \%$ \\
120 & Bluish-violet solid & Sublimated at $\sim 380$ & $82.31 \pm 1.31 \%$ \\
180 & Dark bluish-violet solid & Sublimated at $\sim 400$ & $84.45 \pm 1.24 \%$ \\
240 & Dark bluish-violet solid & Sublimated at $\sim 400$ & $83.68 \pm 1.88 \%$ \\
\hline
\end{tabular}
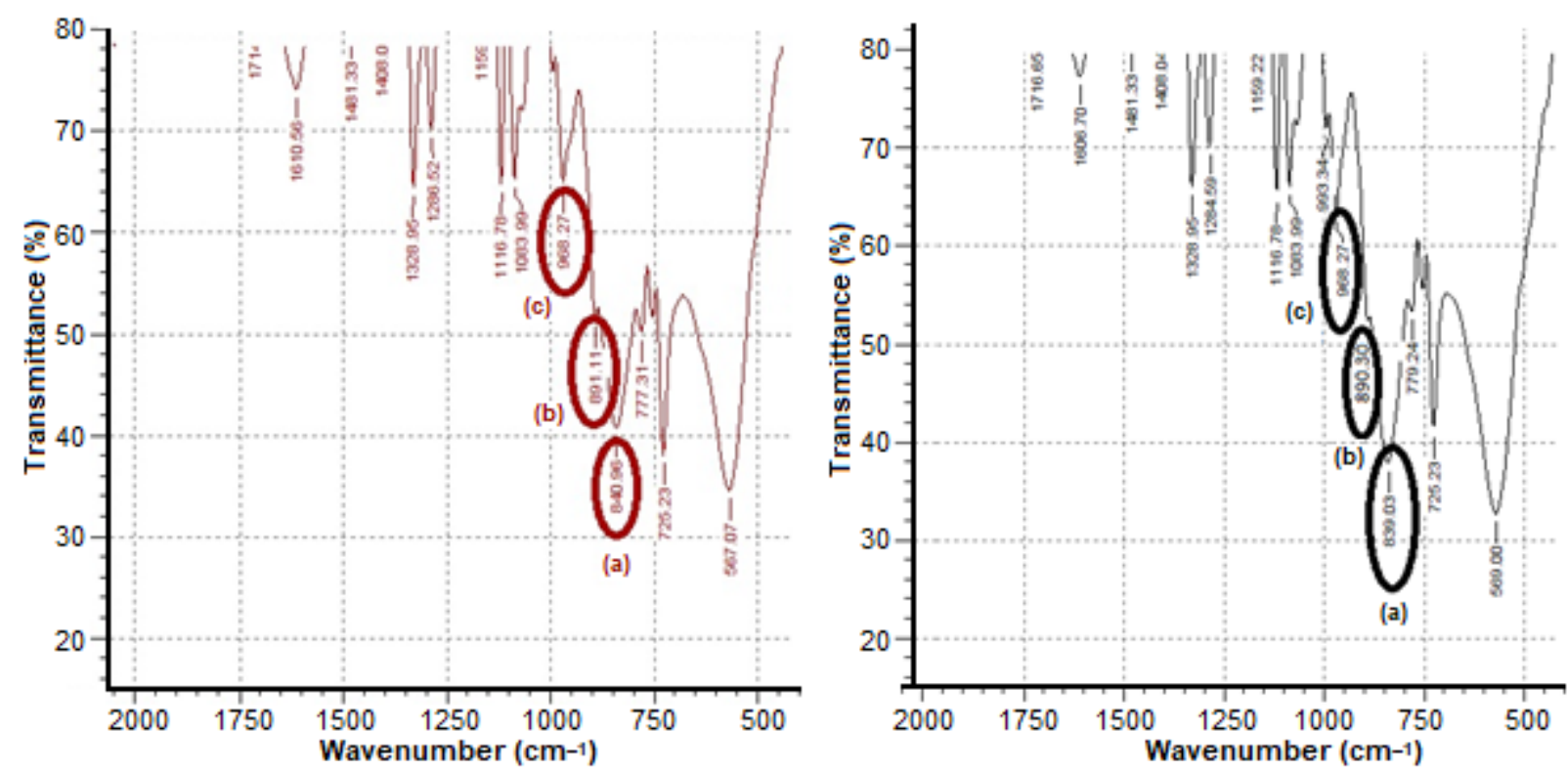

Fig 2. FTIR spectra of Mo-Pc, synthesis temperature $300{ }^{\circ} \mathrm{C}$, time of reaction $180 \mathrm{~min}$ (left) and $240 \mathrm{~min}$ (right), showing main peaks of Mo-Pc (a) $\mathrm{N}$-isoindole (b) Mo-N vibration (c) $\mathrm{Mo}=\mathrm{O}$ stretching 
This pattern was in agreement with the pattern for tungsten phthalocyanine [9] with some shift due to the difference in the metal core. Lines due to free Mo [13] and phthalonitrile [14] were absent from this Mo-Pc pattern.

Fig. 4 presents the diffractogram of Mo-Pc synthesized in conditions of non-stoichiometric molybdenum and phthalonitrile. Excess molybdenum was added in this synthesis. This pattern distinctively differs from Mo-Pc synthetized in optimum condition. We compared this pattern with other patterns of $\mathrm{MoO}_{2}$ [14-15]. Based on the results of these other studies, $\mathrm{MoO}_{2}$ peaks are identified in Fig. 4. These peaks were fused with Mo-Pc peaks. It can be concluded that two forms of molybdenum existed when excess molybdenum was added into the reaction: $\mathrm{Mo}-\mathrm{Pc}$ and $\mathrm{MoO}_{2}$.

Some diffraction lines at the following values of $2 \theta$ : $7.16,12.28,23.84,26.38$, and $28.18^{\circ}$ matched diffraction lines for Mo-Pc, whereas the diffraction lines at 26.38, $36.84,53.42$, and $60.66^{\circ}$ match with diffraction lines from $\mathrm{MoO}_{2}$. Lines due to free Mo [16] and phthalonitrile [17] were absent from this Mo-Pc pattern.

\section{UV-vis Properties of Molybdenum Phthalocyanine}

UV-vis spectrophotometer measurement was carried out in different solutions of Mo-Pc. Measurement of Mo-Pc in $\mathrm{H}_{2} \mathrm{SO}_{4}$ solution was absent due to a strong chemical/solvatochromic effect. Fig. 5 shows the absorption spectra of Mo-Pc in DMF, TFA, and THF.

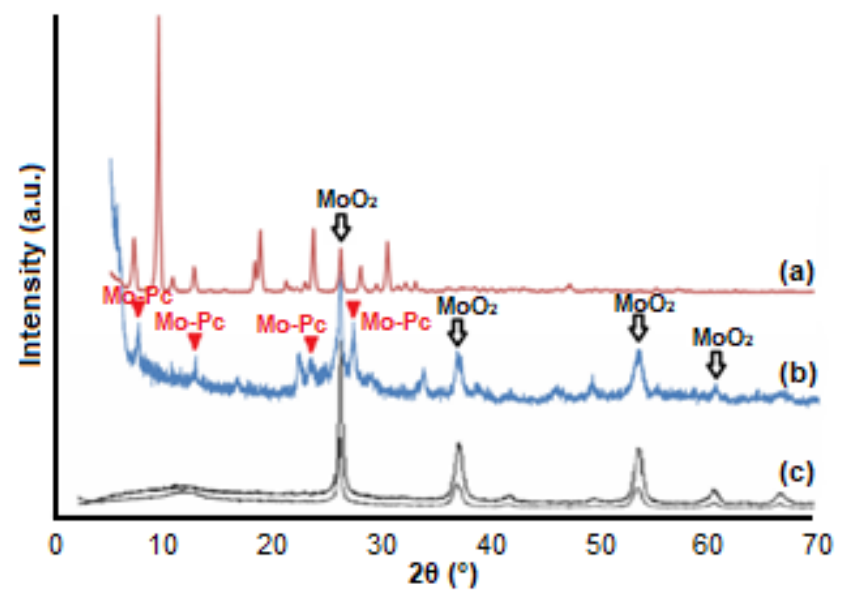

Fig 4. XRD pattern comparison between (a) Mo-Pc in optimized synthesis condition (b) Mo-Pc with excess molybdenum and (c) $\mathrm{MoO}_{2}$ solid [14]
The UV-vis peak of metal phthalocyanine is mainly caused by $\pi-\pi^{*}$ electronic transition. This transition is usually known as Q-band transition and results in peaks in the visible region between 600 and $750 \mathrm{~nm}$ [12]. In this study, Q-band peak appeared as a split absorption band when Mo-Pc was dissolved in THF and DMF. This splitting was due to protonation of Mo-Pc in THF and DMF [12,18]. Splitting was absent when Mo-Pc was dissolved in TFA. Mo-Pc solution was relatively stable for 3 days with no significant changes in absorption value in the Q-band. Mo-Pc did not show charge transfer between metal (Mo) and phthalocyanine rings, whereas other phthalocyanine compounds such as $\mathrm{Mn}-\mathrm{Pc}$ and Fe-Pc are

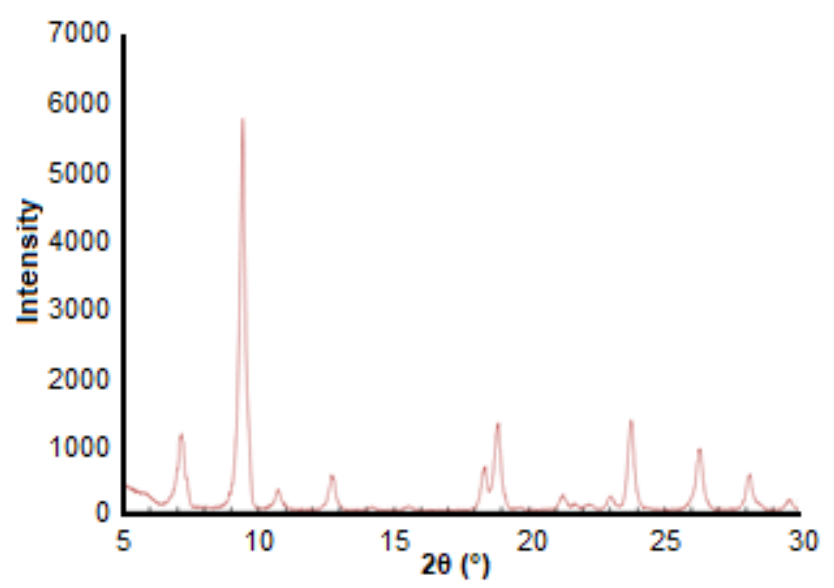

Fig 3. XRD diffractogram of Mo-Pc in optimum condition

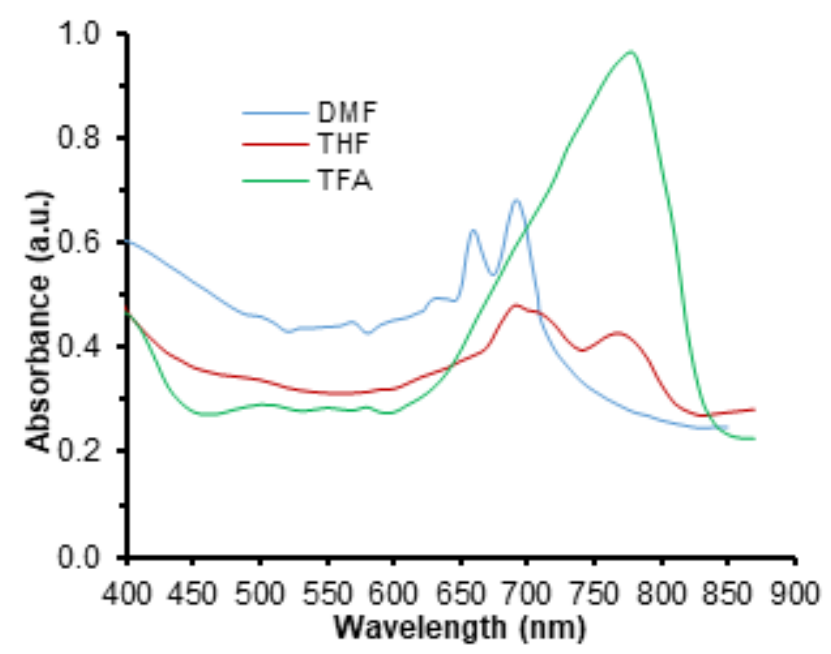

Fig 5. UV-vis spectra of Mo-Pc in three different solvents 
Table 5. Molybdenum content and specific activity of ${ }^{99} \mathrm{Mo}$

\begin{tabular}{lclll}
\hline Target type & $\begin{array}{l}\text { Activity }(\mathrm{mCi}) \text { after } \\
5 \text { days cooling }\end{array}$ & $\begin{array}{l}\text { Mo content in } \\
\text { solution }(\mathrm{g})\end{array}$ & Specific activity & $\begin{array}{l}\text { Enrichment } \\
\text { factor }\end{array}$ \\
\hline $\mathrm{MoO}_{3}(225 \mathrm{mg})$ & 0.40 & $1.5 \times 10^{-1}$ & $2.68 \mathrm{mCi} / \mathrm{g} \mathrm{Mo}$ & - \\
$\mathrm{Mo}^{\mathrm{Pc}}(1 \mathrm{~g})$ & 0.58 & $8.5 \times 10^{-4}$ & $682.35 \mathrm{mCi} / \mathrm{g} \mathrm{Mo}$ & 254.61 \\
\hline
\end{tabular}

well known for their charge transfer and are very unstable in solution form [19-20].

\section{A Preliminary Study of Mo-Pc Irradiation}

Irradiation of $1 \mathrm{~g}$ Mo-Pc resulted in $0.58 \mathrm{mCi}$ of ${ }^{99} \mathrm{Mo}$ in the Mo-Pc target after 5 days of irradiation. We also irradiated natural $\mathrm{MoO}_{3}$ as a control to be compared with Mo-Pc irradiation. According to molar calculation, $1 \mathrm{~g}$ of Mo-Pc contains about $150 \mathrm{mg}$ of elemental Mo, thus $225 \mathrm{mg}$ of $\mathrm{MoO}_{3}$ is equivalent to the content of Mo in $1 \mathrm{~g}$ of Mo-Pc. The yield of irradiation was about $96.3 \%$ from the calculated activity. After several dissolutions with THF and extraction processes into $3 \mathrm{M} \mathrm{NaOH}, 89 \%{ }^{99} \mathrm{Mo}$ remained in the final solution. This yield was far better than other reported results using different types of molybdenum molecules [21-22].

Table 5 indicates that $0.85 \mathrm{mg}$ of Mo was found in the solution by spectrophotometric determination of Mo content [23]. This Mo content was $0.56 \%$ compared to initial Mo content in $1 \mathrm{~g}$ of irradiated Mo-Pc (150 mg). Most of the molybdenum remained in Mo-Pc structure and was not extracted into $\mathrm{NaOH}$ during the SzilardChalmers reaction, indicating that the specific activity of Mo-99 solution could, therefore, be increased.

This preliminary study shows that Mo-Pc irradiation followed by several dissolutions and extraction processes exhibits enrichment in ${ }^{99}$ Mo specific activity. The specific activity could be increased by utilization of Mo-Pc, at 254.61 times higher than irradiation of natural molybdenum oxide. This enrichment factor was equal to that found in one study [22] but slightly less than in another study [21]. However, both of these previously reported results had lower yield compared to Mo-Pc utilization for Mo-99 production as investigated in this study.

Further investigation will be carried out to optimize the production of ${ }^{99} \mathrm{Mo}$ by Szilard-Chalmers reaction.

\section{- CONCLUSION}

Mo-Pc was successfully synthesized with an optimum temperature of synthesis of $300{ }^{\circ} \mathrm{C}$ and $3 \mathrm{~h}$ of reflux. Mo-Pc was sublimated at $400{ }^{\circ} \mathrm{C}$ without undergoing melting when measured with melting point apparatus. FTIR measurement showed characteristic peaks of Mo-N and $\mathrm{Mo}=\mathrm{O}$ at 891 and $968 \mathrm{~cm}^{-1}$ respectively. XRD measurement confirmed that there was no $\mathrm{MoO}_{2}$ in Mo-Pc synthesized at optimum condition. UV-vis absorption spectra of Mo-Pc solution in THF, DMF, and TFA showed Q-band absorption characteristics between 600 and $750 \mathrm{~nm}$. Protonation of Mo-Pc occurred when Mo-Pc was dissolved in THF and DMF, marked by splitting of the absorption peak. This melting point, FTIR and XRD characteristics could be used as purity criteria when performing Mo-Pc synthesis. A preliminary study of Mo-Pc irradiation showed a specific activity of ${ }^{99} \mathrm{Mo}$ could be increased 254.61 times by utilization of Mo-Pc compared to irradiation of natural molybdenum oxide.

\section{- ACKNOWLEDGMENTS}

The authors wish to express their gratitude to Center for Applied Nuclear Science and Technology National Nuclear Energy Agency (PSTNT-BATAN) Management for supporting this research through internal budget for fiscal year 2017 (Budget Code 3449.001.010) and also to Ms. Khoerunnisa (Bandung State Polytechnic) and Mr. Yanuar (PSTNT-BATAN) for laboratory assistance at PSTNT-BATAN.

\section{- REFERENCES}

[1] Pillai, M.R.A., Dash, A., and Knapp, F.F.R., 2013, Sustained availability of ${ }^{99 \mathrm{~m}} \mathrm{Tc}$ : Possible paths forward, J. Nucl. Med., 54 (2), 313-23.

[2] IAEA, 2013, Non-HEU Production Technologies for Molybdenum-99 and Technetium-99m, $1^{\text {st }}$ ed., 
International Atomic Energy Agency, Vienna, Austria.

[3] Le, V.S., 2014, ${ }^{99 \mathrm{~m}} \mathrm{Tc}$ generator development: Up-todate ${ }^{99 \mathrm{~m}} \mathrm{Tc}$-recovery technologies for increasing the effectiveness of ${ }^{99} \mathrm{Mo}$ utilization, Sci Technol Nucl. Ins., 2014, 345252.

[4] Dash, A., Knapp, F.F.R., and Pillai, M.R., 2013, ${ }^{99} \mathrm{Mo} /{ }^{99 \mathrm{~m}} \mathrm{Tc}$ separation: An assessment of technology options, Nucl. Med. Biol., 40 (2), 167-176.

[5] Kadarisman, and Adang, H.G., 2011, Unjuk kerja generator radioisotop ${ }^{99} \mathrm{Mo} /{ }^{99 \mathrm{~m}} \mathrm{Tc}$ dengan radioaktivitas ${ }^{99} \mathrm{Mo} 600$ dan $800 \mathrm{mCi}$ berbasis PZC, Urania, 17 (1), 26-33.

[6] Dikiy, N.P., Dovbnya, A.N., Krasnoslsky, N.V., Lyashko, Y.V., Medvedeva, E.P., Medvedev, D.V., Uvarov, V.L., and Fedorets, I.D., 2015, The use of molybdenum oxide nanoparticles for production of free isotope Mo-99, Probl. Atomic Sci. Technol., 100 (6), 154-156.

[7] de Crowley, L.A.F., Lara, R.O., Millan, S.S., and Maddock, A.G., 1979, Recoil effects in some molybdenum complexes, Radiochim. Acta, 26, 39-40.

[8] Ilyin, A.P., Korovin, S.A., Menshikov, L.I., Petrunin, V.F., Semenov, A.N., and Chuvilin, D.Y., 2015, Usage of molybdenum nanocrystalline powder for radioisotope production, Physics Procedia, 72, 548551.

[9] Setiawan, D., 2000, Synthesis and Characterization of Tungsten-Phtalocyanine as Target Material of High Specific Activity W-188, Proceeding of Scientific Meeting in Radiation and Isotopes Technology Development, 269-273.

[10] Edmondson, S.J., and Mitchell, P.C.H., 1986, Molybdenum phthalocyanine, Polyhedron, 5 (1-2), 315-317.

[11] Nampira, Y., and Anggraini, D., 2012, Penggunaan pereaksi xylenol orange dalam analisis molybdenum menggunakan metode spektrophotometri, Urania, 18 (2), 88-95.

[12] Ghani, F., Kristen, J., and Riegler, H., 2012, Solubility properties of unsubstituted metal phthalocyanines in different types of solvents, J. Chem. Eng. Data, 57 (2), 439-449.
[13] Achar, B.N., Fohlen, G.M., Lokesh, K.S., and Kumar, T.M.M., 2005, GC-MS studies on degradation of copper phthalocyanine sheet polymer, Int. J. Mass Spectrom., 243 (3), 199-204.

[14] Naouel, R., Touati, F., and Gharbi, N., 2012, Control of the morphology of molybdenum dioxide nanoparticles, E-J. Chem., 9 (1), 233-239.

[15] Sarno, M., Garamella, A., Cirillo, C., and Ciambelli, P., 2014, $\mathrm{MoO}_{2}$ synthesis for LIBs, Chem. Eng. Trans., 41, 307-312.

[16] Ravisubramanian, S., Azad, A., and Sakthinathan, G., 2013, Coating of synthesized molybdenum nanopowder on aluminium, Asian J. Sci. Res., 6 (3), 603-608.

[17] Chen, X., Shan, S., Liu, J., Qu, X., and Zhang, Q., 2015, Synthesis and properties of high temperature phthalonitrile polymers based on $\mathrm{o}, \mathrm{m}, \mathrm{p}$ dihydroxybenzene isomers, RSC $A d v$., 5 (98), 80749-80755.

[18] Tuhl, A., Manaa, H., Makhseed, S., Al-Awadi, N., Mathew, J., Ibrahim, H.M., Nyokong, T., and Behbehani, H., 2012, Reverse saturation absorption spectra and optical limiting properties of chlorinated tetrasubstituted phthalocyanines containing different metals, Opt. Mater., 34 (11), 1869-1877.

[19] Roth, F., Herzig, M., Lupulescu, C., Darlatt, E., Gottwald, A., Knupfer, M., and Eberhardt, W., 2015, Electronic properties of Mn-Phthalocyanine$\mathrm{C}_{60}$ bulk heterojunctions: Combining photoemission and electron energy-loss spectroscopy, J. Appl. Phys., 118 (18), 185310.

[20] Glaser, M., Peisert, H., Adler, H., Polek, M., Uihlein, J., Nagel, P., Merz, M., Schuppler, S., and Chasse, T., 2015, Transition-metal phthalocyanines on transition-metal oxides: Iron and cobalt phthalocyanine on epitaxial $\mathrm{MnO}$ and $\mathrm{TiO}_{\mathrm{x}}$ films, $J$. Phys. Chem. C, 119 (49), 27569-27579.

[21] van Dorp, J.W.J., Mahes, D.S., Bode, P., Wolterbeek, H.T., Denkova, A.G., and SerraCrespo, P., 2018, Towards the production of carrier-free ${ }^{99} \mathrm{Mo}$ by neutron activation of ${ }^{98} \mathrm{Mo}$ in 
molybdenum hexacarbonyl-Szilard-Chalmers enrichment, Appl. Radiat. Isot., 140, 138-145.

[22] Tomar, B.S., Steinebach, O.M., Terpstra, B.E., Bode, P., and Wolterbeek, H.T., 2010, Studies on production of high specific activity ${ }^{99} \mathrm{Mo}$ and ${ }^{90} \mathrm{Y}$ by Szilard Chalmers reaction, Radiochim. Acta, 98, 499506.
[23] Febrian, M.B., Mulyati, T.S., Suherman, A., Adventini, N., Setiadi, Y., Setiawan, D., and Aziz, A., 2018, Spectrophotometric determination of molybdenum content in ${ }^{99 \mathrm{~m}} \mathrm{Tc}$ solution via MoTGA-KSCN complexes formation, JSTNI, 19 (2), 71-80. 